\title{
Correlation of the F129L mutation in Pyrenophora teres, the pathogen of net blotch of barley, with the efficacy of QoI fungicides
}

\author{
Qasim Abdulla Marzani ${ }^{* 1,2}$, Philip Swarbrick ${ }^{2}$, Stephen Rossall ${ }^{2}$ \\ ( ${ }^{1}$ Department of Plant Protection, College of Agriculture, University of Salahaddin, Erbil, Southern Region of \\ Kurdistan, Iraq.) \\ $\left({ }^{2}\right.$ School of Biosciences, University of Nottingham, Sutton Bonington Campus, Loughborough, LE12 5RD, UK.) \\ Corresponding Author: Qasim Marzani
}

\begin{abstract}
The cytochrome b F129L mutation has been detected in several plant pathogens including Pyrenophora teres, the causal agent of net blotch of barley. Isolates of this pathogen were obtained from different parts of the UK and from other European countries for determination of the presence of F129L mutation and its effect on the performance of several QoI fungicides. Results from in vitro assays of fungicides tested showed that the pathogen was inhibited on QoI amended agar medium but the mutations compromised fungal inhibition: isolates with F129L mutation had greater EC50 values than wild type isolates for all QoI fungicides tested. Experiments carried out in planta using barley seedlings also showed variation between the level of disease control provided by different QoI fungicides; for example picoxystrobin showed greater efficacy than azoxystrobin. It is concluded that determination of the effects of fungicide resistance mutations should be based on genotyping, combined with both in vitro and in planta evaluations of activity.
\end{abstract}

Key words: Pyrenophora teres, barley, QoI fungicides, F129L mutation

\section{Introduction}

Barley (Hordeum vulgare L.) is an important cereal grain crop which ranks fifth globally among all crops in dry matter production [1]. Barley production was estimated in 2008/09 at $6.2 \mathrm{Mt}$ in the UK and $156 \mathrm{Mt}$ worldwide, which was the highest on record (HGCA). Barley has an important role in world agriculture, with high demand from brewery, distilling and animal feed industries. The crop is commonly attacked by Pyrenophora teres Drechs., a necrotrophic pathogen, causing net blotch disease. The disease is gaining economic importance and increased incidence has been reported from countries throughout the world during recent decades [2]. This may reflect the popularity of susceptible cultivars, in combination with monoculture and intensive management practices [3]. Losses due to net blotch are typically from 10 to $40 \%$ but may reach much higher levels under favourable environmental conditions [4].

Fungicides play an important role in crop protection. Two major groups of site-specific systemic fungicides are presently widely used to control of cereal diseases. The triazole-based fungicides, which inhibit the $\alpha$-C14 dimethylation step in fungal ergosterol biosynthesis, belong to the group known as demethylation inhibitors (DMIs) [5], and quinone outside inhibitors (QoIs) (also called strobilurins), which inhibit mitochondrial respiration [6]. The performance of many modern fungicides has been affected to some degree by the evolution of strains of pathogens exhibiting resistance or reduced sensitivity. Much research has shown that the development of resistance is greatly enhanced by the continued use of fungicides with single specific mechanisms of action $[7 ; 8 ; 9]$. The intensive use of fungicides and application over large areas has, in some instances, caused partial or total loss of efficacy due to the emergence of pathogen phenotypes that have higher fitness in a fungicide-treated environment [10]. The incidence of initially rare mutants in the pathogen population will build up when selective pressure is applied by application of fungicides. This is because resistant isolates have better adaptation in the presence of fungicide compared to sensitive isolates [11]. Resistance to QoIs has developed in several cereal pathogens and two amino acid substitutions have been detected in the cytochrome $b$ gene in plant pathogens that show resistance to QoI fungicides. One such mutation leads to a substitution of glycine by alanine at amino acid position 143 (G143A). This is the main mechanism known to confer resistance to QoIs and is found in a broad range of pathogenic fungi and oomycetes, such as Blumeria graminis f. sp. tritici [12; 13], Plasmopara viticola [14], and Mycosphaerella graminicola [15]. Another mutation at amino acid position 129, which leads to the substitution of phenylalanine by leucine (F129L), confers resistance in plant pathogens including Alternaria solani [16], Pythium aphanidermatum [17], and Plasmopara viticola [13; 18]. To date, only the F129L mutation has been found in P. teres [15; 19]. Investigations have focused on the presence of the F129L mutation in populations of net blotch of barley, found in Europe since 2003 and has been found to reduce the efficacy of some QoI fungicides [20; 9]. Despite the importance of net blotch of barley in the UK, information on the F129L mutation and its impact on control by 
QoI fungicides is lacking. Therefore, the aim of this research was to investigate the occurrence of the F129L mutation in populations of $P$. teres from the UK, to determine the level of resistance to QoI fungicides in vitro and to ascertain how the mutation might impact on the efficacy of control of net blotch disease of barley.

\section{a. Pyrenophora teres isolates}

\section{Materials And Methods}

Initially, thirteen isolates of $P$. teres were obtained as cultures from different research centres in the UK and mainland Europe. The first group of isolates obtained and their sources are shown in Table 1. Six isolates (3 purported F129L mutants and 3 purported wild types) were obtained from DuPont, France. Five isolates of unknown pedigree (18, 83, 458, 557 and 1782) were from Scottish Agriculture Science Agency (SASA) and two unknown isolates from National Institute for Agricultural Botany (NIAB).

The second group of isolates were obtained from barley leaf samples of growing season 2008-2009 provided by members of The Arable Group (TAG). Leaf samples were received from 10 different areas of the Midlands and eastern England. One pathogen isolate was taken from each leaf and cultured on potato dextrose agar (PDA). Polymerase Chain Reaction (PCR) and DNA sequence analysis was used to detect the mutation F129L in unknown-pedigree isolates and to confirm the presence or absence of the mutation in other isolates from different research centres. Details are given in Table 1.

Table 1. Isolates ${ }^{1,2}$ of $P$. teres, barley cultivar source, their reported sensitivity and provider (with original geographical source in parentheses) and sequence results.

\begin{tabular}{|c|c|c|c|}
\hline Isolate ID & Source & $\begin{array}{l}\text { Purported } \\
\text { QoI sensitivity }\end{array}$ & $\begin{array}{l}\text { Sequence } \\
\text { result }\end{array}$ \\
\hline $\mathrm{H} 1 / 2$ & DuPont (Hungary) & Wild type & WT \\
\hline 1522 & DuPont (UK) & Wild type & WT \\
\hline 1530 & DuPont (France) & Wild type & WT \\
\hline 1534 & DuPont (Belgium) & Mutant (F129L) & F129L \\
\hline 1539 & DuPont (France) & Mutant (F129L) & WT \\
\hline $\mathrm{F} 20 / 3$ & DuPont (France) & Mutant (F129L) & F129L \\
\hline 18 & CABI - UK & Unknown & WT \\
\hline 83 & Hampshire - UK & Unknown & WT \\
\hline 458 & Suffolk - UK & Unknown & WT \\
\hline 557 & North Humberside - UK & Unknown & WT \\
\hline 1782 & East Lothian - UK & Unknown & WT \\
\hline Pt 01-02 & NIAB (UK) & Unknown & WT \\
\hline Pt 07-1 & NIAB (UK) & Unknown & WT \\
\hline OTV-1 & Oxfordshire-Thames Valley & Unknown & F129L \\
\hline MR2-1 & The Arable Group- Morley & Unknown & F129L \\
\hline MR1-1 & The Arable Group- Morley & Unknown & F129L \\
\hline $\mathrm{LN}-2$ & Linby-Nottinghamshire & Unknown & F129L \\
\hline HSS-2 & TAG Hampshire, Sutton Scotney & Unknown & WT \\
\hline GL-2 & Glentham- Lincolnshire & Unknown & F129L \\
\hline COL-2 & Caythorpe-Lincolnshire & Unknown & F129L \\
\hline CAYL-3 & Caythorpe-Lincolnshire & Unknown & F129L \\
\hline BOT-1 & Stapenhill, Burton on Trent, Staffordshire & Unknown & WT \\
\hline THM-2 & TAG-Hampshire & Unknown & F129L \\
\hline
\end{tabular}

${ }^{1}$ Isolates 1-13 donated as cultures in 2007.

${ }^{2}$ isolates 14-23 was collected as infected leaves in 2008 .

\section{b.In vitro sensitivity bioassay}

To investigate the activity of QoI fungicides against wild type and mutant isolates of $P$. teres, a group of four strobilurins (Table 2) were tested in vitro. These were selected as they represent the only products available which contained single QoI active ingredient. For this purpose, Petri dishes were used (25-well, 18 mm diameter wells; Sterilin, Staffordshire, UK). Potato Dextrose Agar (PDA) was amended fungicide to a concentration of $5 \mathrm{mg} \mathrm{L}^{-1}$ active ingredient added to the agar at $55^{\circ} \mathrm{C}$, leaving the last well unamended as an untreated control. Using a sterile cork borer, the amended media were inoculated with circular mycelium plugs of $4 \mathrm{~mm}$ diameter taken from the growing edges of 7-day old cultures of isolates of the pathogen grown on 
PDA. The plugs were placed mycelium-down on the centre of the wells and then incubated in the dark with temperature of $20 \pm 2^{\circ} \mathrm{C}$. Growth of the fungi was monitored daily until the fungus in unamended control wells reached the edge of the well. Radial growth of the pathogen was measured using digital callipers at two different angles at $90^{\circ}$ to each other and the mean colony diameter calculated. After a deduction of $4 \mathrm{~mm}$ was made to account for the mycelium plug, percentage inhibition for each treatment was calculated compared to the untreated control. This preliminary investigation provided information on the relative sensitivity of $P$. teres isolates to QoIs. It proceeded in more detailed analysis based on determination of the fungicide concentration needed to reduce mycelial growth by $50 \%$ (EC50).

Table 2. Strobilurin Fungicides used in both in vitro and in planta assays.

\begin{tabular}{llll}
\hline $\begin{array}{l}\text { Product } \\
\text { name }\end{array}$ & $\begin{array}{l}\text { Active } \\
\text { ingredient }\end{array}$ & Concentration $\left(\mathrm{g} \mathrm{L}^{-1}\right)$ & Field application rate $\left(\mathrm{Lha}^{-1}\right)$ \\
\hline Twist & Trifloxystrobin & 125 & 2 \\
Comet & Pyraclostrobin & 250 & 1 \\
Amistar & Azoxystrobin & 250 & 1 \\
Acanto & Picoxystrobin & 250 & 1 \\
\hline
\end{tabular}

\section{c. Determination of EC50}

Twenty five-well Petri dishes were used to determine EC50 for isolates of $P$. teres. For this purpose, 10 fungicide concentrations were prepared ranging from 100 to $0 \mathrm{mg} \mathrm{L}^{-1}$. To achieve this, PDA medium was used and the fungicide was added at $55^{\circ} \mathrm{C}$. The highest concentration, $100 \mathrm{mg} \mathrm{L}^{-1}$, was prepared and from this other concentrations were prepared by serial dilution. The concentrations were: 100, 33.33, 11.11, 3.7, 1.24, 0.41, $0.14,0.046,0.015$ and $0.00 \mathrm{mg} \mathrm{L}^{-1}$.

The wells were inoculated with $4 \mathrm{~mm}$ mycelium plugs taken from the edges of 7-day old cultures of $P$. teres grown on PDA. The experiment was replicated three times using two 25 -well plates per replicate. The plates were incubated at $20 \pm 2^{\circ} \mathrm{C}$ in the dark for 3-5 days depending on the isolate. Radial growth was measured by using digital callipers as described above. The percentage inhibition at each concentration was measured, relative to the untreated control, and from that EC50 was determined using probit analysis.

\section{d.In planta assessment of fungicides}

To evaluate the efficacy of fungicides on P. teres control on barley plants, the susceptible cultivar Pearl was grown in $9 \mathrm{~cm}$ pots at a density of 10 plants per pot. Ten days after emergence the plants were sprayed with fungicides as a protective spray. The generic name, common name and chemical class of these fungicides are presented in Table 3, with the active ingredient concentration and the full field application rate. Fungicides were applied at the manufacturers recommended rates in a volume of water equivalent to $200 \mathrm{~L} \mathrm{ha}^{-1}$. Two days after treatment, the plants were inoculated with $P$. teres at $10^{4}$ units $\mathrm{mL}^{-1}$ as described above. Inoculation with pure conidial suspensions was not possible as some isolates sporulated poorly, despite attempts to culture them on a range of media under differing environmental conditions. Control plants were treated the same as experimental plants but not treated with fungicides. After 10 days, the disease incidence was assessed visually by evaluating necrosis using an evaluation 1-10 scale [21] and data manipulated to the percentage of fungicide efficacy (\% of disease control) using the following formula:

$\%$ disease control $=\frac{\text { Disease degree of untreated control }- \text { disease degree of treated }}{\text { Disease degree of untreated control }} \times 100$

\section{e. Statistical analysis}

SPSS v16 software (SPSS Inc., IBM Company, Chicago, Illinois, USA) was used for probit analysis for determination of EC50, using $\log 10$ of the concentration of fungicides applied.

All other data were statistically analysed by ANOVA using GenStat v11 (VSN International Ltd., UK). Multiple mean comparisons were done using the Fisher's Least Significant Difference test $(P<0.05)$.

\section{a.In vitro sensitivity bioassay}

\section{Results}

In order to evaluate fungicides in vitro, mycelium discs of each isolate were grown on PDA medium amended with $5 \mathrm{mg} \mathrm{L}^{-1}$ fungicide active ingredient. The effect of the fungicides on the inhibition of the growth of $P$. teres isolates in vitro was significantly different. The results showed that the performances of trifloxystrobin, azoxystrobin and picoxystrobin on the wild type isolates 1530 and 1782 and on mutant isolate 1534 were significantly higher than with other isolates at $5 \mathrm{mg} \mathrm{L}^{-1}$ (Fig. $1 \mathrm{a}$, c, and d). The activity of 
trifloxystrobin, azoxystrobin and picoxystrobin against mutant isolates THM-2, MR1-1 and Cayl-3 were less pronounced. Interestingly, trifloxystrobin and azoxystrobin both showed low efficacy against wild type isolate

1539. Notably, the efficacy of picoxystrobin on isolate 1539 is as low as mutant isolate Cayl-3. However, the performance achieved by pyraclostrobin, although it was less pronounced on isolate 1539, outperformed other fungicides regardless of the sensitivity of the isolates (Fig. 1 b). Pyraclostrobin was the most effective fungicide, inhibiting growth by $85.7-100 \%$ at this concentration.
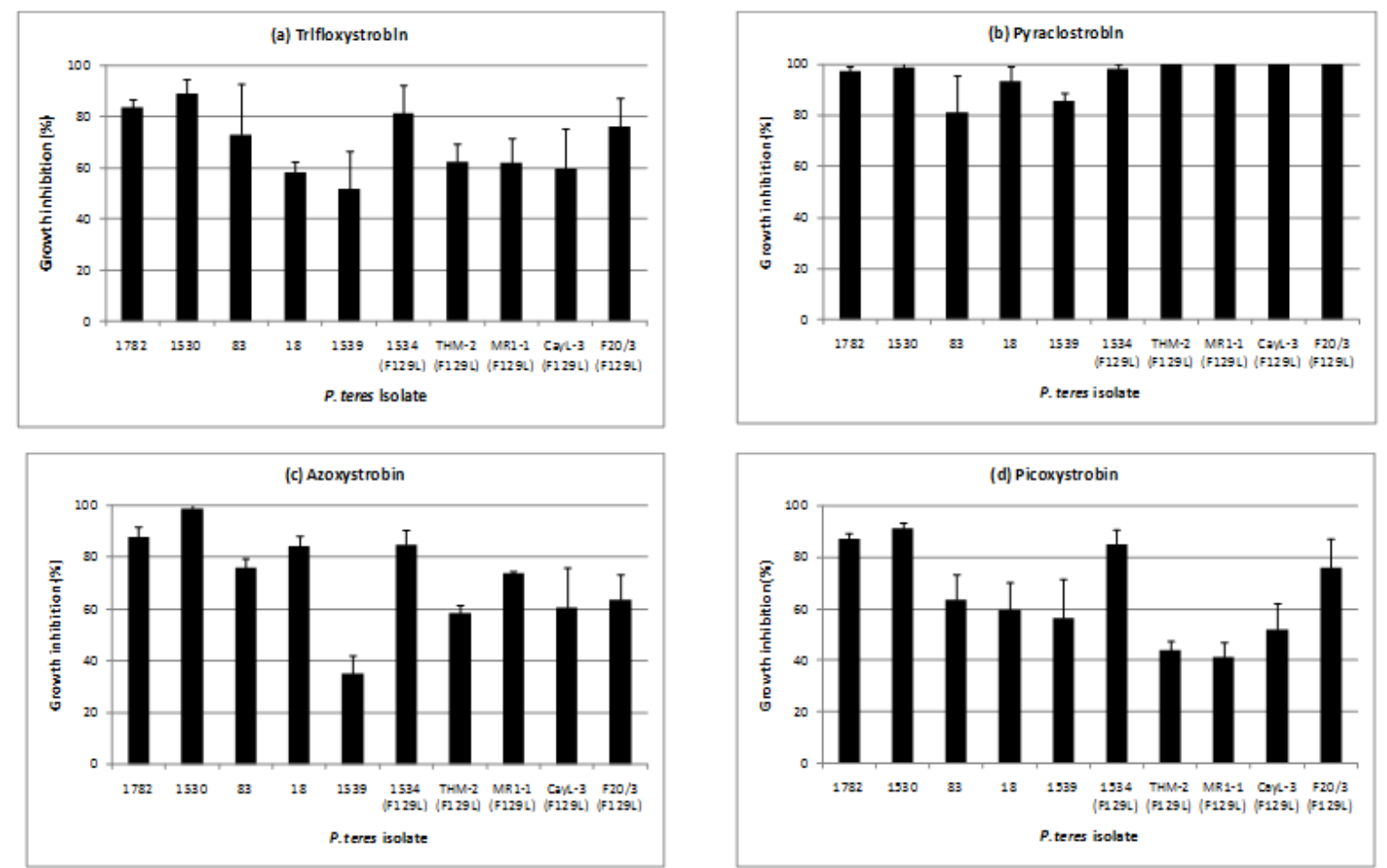

Figure 1. In vitro fungal growth inhibition assessment of $4 \mathrm{QoI}$ fungicides on the growth of $P$. teres isolates. The PDA medium was amended with $5 \mathrm{mg} \mathrm{L}^{-1}$ of each fungicide. Inhibition of mycelium growth caused by trifloxystrobin (a), pyraclostrobin (b), azoxystrobin (c), and picoxystrobin (d). Data represent means of 4 replicates, error bars represent standard deviation.

\subsection{EC 50}

The concentration which is calculated to inhibit the growth of the fungus by half, EC50, was measured in vitro, inhibition to the untreated control. This was done to quantify more precisely the sensitivity of several isolates of $P$. teres towards the fungicides tested. The results showed that mutant isolates were found to have higher EC50 values towards QoIs than wild type isolates (Fig. 2). Mutant Isolates 1534, THM-2, MR-1-1, and Cayl-3 had EC50 values 6.27, 1.37, 1.93, and $2.41 \mathrm{mg} \mathrm{L}^{-1}$ respectively towards trifloxystrobin. In contrast, wild type isolates showed EC50s of less than $1.1 \mathrm{mg} \mathrm{L}^{-1}$. Interestingly, some of the mutant and wild type isolates showed little difference in their EC50 towards pyraclostrobin, which was very low and variable, reflecting the sensitivity of the fungus to this QoI fungicide (it generally caused complete inhibition at $5 \mathrm{mg} \mathrm{L}^{-1}$ in vitro, Fig. 2 b). Comparing the sensitive isolates, the differences in intrinsic activity is small among the QoIs, but bigger when comparing the resistant isolates. 

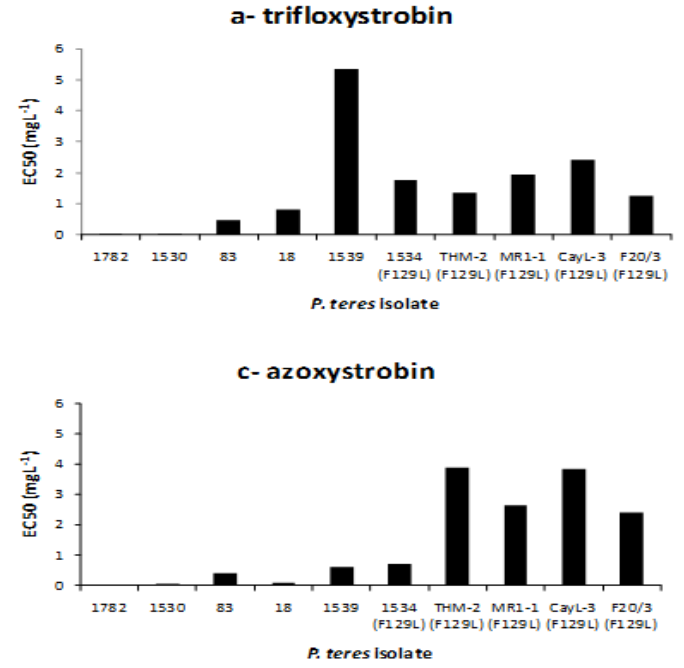

b- pyraclostrobin

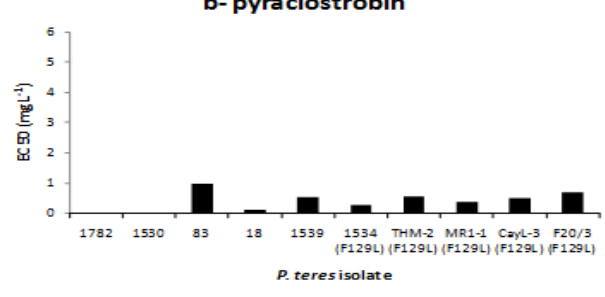

d- picoxystrobin

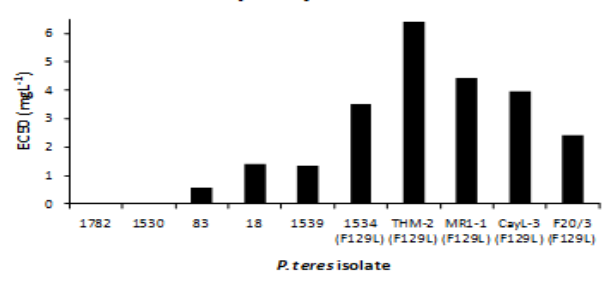

Figure 2. EC50 of isolates of $P$. teres with 4 QoI fungicides measured by agar-amended technique and calculated by probit analysis proportional to untreated control.

\subsection{In planta assessment of fungicides}

The same group of fungicides were assessed for their efficacy as a protective application against $P$. teres infection of barley plants (applied two days before inoculation). The effect of the fungicides on the percentage disease control was significantly different between isolates. The impact of fungicide application on seven P. teres isolates in planta showed a different pattern from that of the in vitro assessments (Fig. 3). Disease control obtained by trifloxystrobin, pyraclostrobin and azoxystrobin was greatly affected by the F129L mutation. The results were quite diverse on both wild type and mutant isolates. The highest disease control obtained by trifloxystrobin was on mutant isolates MR-1-1 (attaining 86.6\% control) and 1534 (77.5\%). Its performance, although high on wild type isolate 1782, showed low efficacy on wild type isolate 1530; similar to that shown on mutant isolate Cayl-3, and showed lower efficacy against mutant isolate THM-2 and the lowest against isolate 1539 (Fig. 3 a). Pyraclostrobin, which was the best performing strobilurin in vitro, failed to give a good control on most of mutant isolates but it gave good control of all wild type isolates tested (Fig. $3 \mathrm{~b}$ ). Interestingly, azoxystrobin gave good control of wild type isolates $1530(91.7 \%)$ and $1782(91.8 \%)$ and to mutant isolate MR1-1 (85.3\%) but failed to give high control with the wild type isolate $1539(40.7 \%)$ and mutant isolates THM-2 (24.9\%), Cayl-3 (53\%) and 1534 (42.1\%) (Fig. $3 \mathrm{c}$ ). The performance of picoxystrobin showed a similar response to that of pyraclostrobin to give the highest disease control on wild type isolates (Fig. $3 \mathrm{~d}$ ). However its performance, although relatively good against mutant isolate Cayl-3, was less effective against mutant isolates 1534, THM-2, and MR1-1.
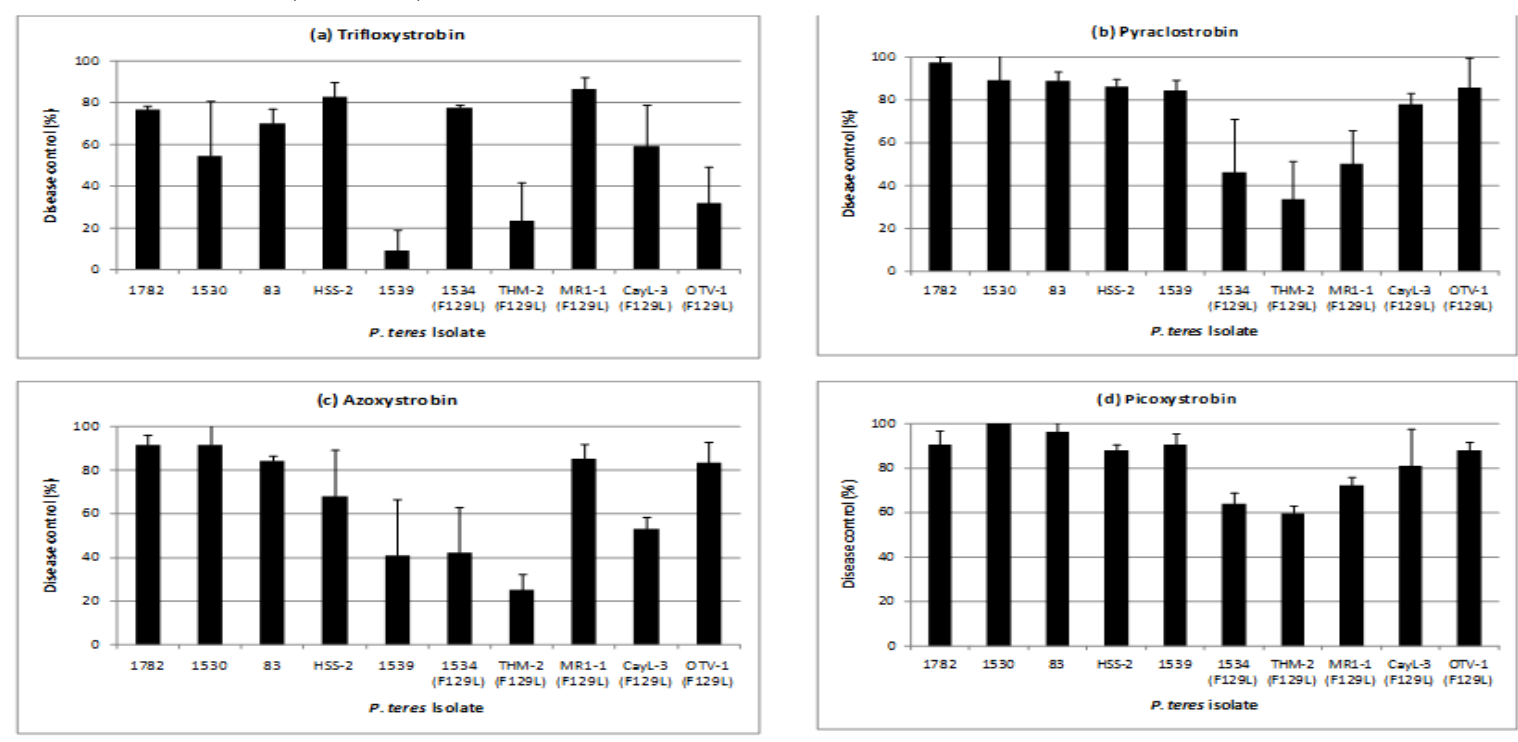

Figure 3. In planta disease assessment of 4 QoI fungicides on the growth of $P$. teres isolates as percentage disease control. Control achieved by trifloxystrobin (a), pyraclostrobin (b), azoxystrobin (c), and picoxystrobin (d). Data represent means of 4 replicates, error bars represent standard deviation. 


\section{Discussion}

The F129L mutation has affected the efficacy of QoI fungicides tested in this work, but had no consistent effect on phenotypic fitness parameters examined. The in vitro studies revealed that QoIs poses different intrinsic activities and inhibited the growth of the fungal pathogen to different extents, with, for instance, pyraclostrobin being more inhibitory than the other fungicides tested. However, efficacy of QoIs against $P$. teres in planta was compromised to some extent. Nevertheless, there was not total failure of fungal control reported, as with the G143A mutation in M. graminicola [22]. [18] emphasised that different amino acid changes in the target protein can cause different levels of resistance. They further confirmed that the G143A mutation caused much higher levels of resistance to QoIs than the less common F129L mutation. [20] reported that in P.teres, an intron in the cytochrome b gene, immediately after the codon for the amino acid in position 143 , was present. The G143A mutation would prevent splicing out of the intron, prior to processing pre-mRNA to mRNA, thereby disrupting functionality of the cytochrome $\mathrm{b}$ protein, leading to a lethal event. Thus the G143A mutation is unlikely occur in P. teres. According to FRAC reports, in 70 pathogens exhibiting a high level of resistance, this was shown to be the result of a single G143A mutation, while the F129L mutation generally caused a much lower degree of resistance [8]. The results obtained in this study are similar of those obtained by [23] who reported that good field protection of barley plants against net blotch was achieved with QoI fungicides (picoxystrobin, pyraclostrobin, and azoxystrobin). They further added that for eradication purpose, picoxystrobin and pyraclostrobin achieved the best control although this type of usage is not recommended for QoIs. [24] stated that pyraclostrobin outperformed azoxystrobin and its performance was not affected by the mutation F129L and provided very good control of net blotch disease in fields with different frequency of the F129L in populations of P. teres in 2005 and 2006 in France. Furthermore, sensitivity studies in transformed strains of Saccharomyces cerevisiae have shown that the different QoIs are not equally affected by the F129L mutation [25]. However, many authors emphasise a need for caution on this issue and advise more research before confirmation that QoIs will continue to work well.

[20] reported that EC50 values of P. teres isolates collected across Europe between 2003 and 2005 were varied and found that the majority of F129L isolates displayed higher EC50 values than wild types. They also stated that some wild type isolates displayed relatively high EC50 values without the presence of F129L mutation. In the results presented here, isolate 1539 was reported to be a QoI mutant, but showed the wild type codon. This isolate, however, showed an insensitive phenotype to the four QoI fungicides tested. Sensitivity of $P$. teres to QoI fungicides may therefore be mediated by factors other than the presence or absence of the F129L mutation.

\section{Conclusions}

The results showed that the F129L mutation is widespread within populations of $P$. teres in the UK and present over a wide geographical extent. Different levels of QoI fungicide efficacy as observed among mutants, indicating that the mutation has variable effects depending on the strain of the pathogen. From the results of this study it is apparent that in vitro studies do not always reflect fungicide performance in planta. Therefore, care is needed in evaluating fungicide performance from genotyping, in vitro and/or in planta experiments. A combination of these approaches is important. It can also be concluded that some QoI fungicides still give good protection against net blotch in barley, despite the presence of the F129L mutation.

\section{Acknowledgements}

The authors thank The Arable Group (TAG) for supplying barley leaf samples from their surveys and Science and Advice for Scottish Agriculture (SASA) and National Institute for Agricultural Botany (NIAB) for providing cultures. We also thank Mike Ashworth and Benjamin Perotin, of DuPont UK and France respectively, for supplying isolates of $P$. teres. Funding from the International Office, University of Nottingham, the Government of Southern Region of Kurdistan and the Ministry of Higher Education of Iraq is gratefully acknowledged.

\section{References}

[1] Baik B K, Ullrich S E. Barley for food: Characteristics, improvement, and renewed interest. Journal of Cereal Science 48, 233-42 (2008).

[2] Arabi M I E, Al-Safadi B, Charbaji T. Pathogenic variation among isolates of Pyrenophora teres, the causal agent of barley net blotch. Journal of Phytopathology-Phytopathologische Zeitschrift 151, 376-82 (2003).

[3] Carmona M, Barreto D, Moschini R, Reis E. Epidemiology and Control of Seed-borne Drechslera teres on Barley. Cereal Research Communications 36, 637-45 (2008).

[4] Mathre D E. Compendium of barley diseases, second edition The American Phytopathological Society, St. Paul, Minnesota, United States 90 pp. (1997).

[5] Gisi U, Chin K M, Knapova G, Farber R K, Mohr U, Parisi S, Sierotzki H Steinfeld U. Recent developments in elucidating modes of resistance to phenylamide, DMI and strobilurin fungicides. Crop Protection 19, 863-72 (2000). 
[6] Chin K M, Chavaillaz D, Kaesbohrer M, Felsenstein F G. Characterizing resistance risk of Erysiphe graminis f. sp. tritici to strobilourins. Crop Protection 20, 87-96 (2001).

[7] Fraaije B A, Burnett F J, Clark W S, Lucas, J A. Development and field testing of fungicide anti-resistance strategies, with particular reference to strobilurin QoI group of fungicides. [Bulletin] HGCA Project Report. Home Grown Cereals Authority, London, UK. 392, 112 pp. (2006).

[8] Brent K J, Hollomon D W. Fungicide resistance in crop pathogens: How can it be managed? Fungicide Resistance Action Committee, FRAC, $2^{\text {nd }}$ revised edition, Brussels, Belgium (2007a).

[9] Jorgensen L N. Resistance situation with fungicides in cereals. Zemdirbyste-Agricuture 95, 373-8 ( 2008).

[10] Shaw M W. Models of the effects of dose heterogeneity and escape on selection pressure for pesticide resistance. Phytopathology 90, 333-9 (2000).

[11] Brent K J, Hollomon D W. Fungicide resistance: The assessment of risk. Fungicide Resistance Action Committee, FRAC, $2^{\text {nd }}$ revised edition, Brussels, Belgium (2007b).

[12] Sierotzki, H, Wullschleger, J, Gisi, U. Point mutation in cytochrome b gene conferring resistance to strobilurin fungicides in Erysiphe graminis f. sp. tritici field isolates. Pesticide Biochemistry and Physiology 68, 107-12 (2000).

[13] Heaney S P, Hall A A, Davis S A and Olaya G. Resistance to fungicides in the QoI-STAR cross-resistance group: current perspectives. Proc Brighton Crop Prot Conf - Pest and Diseases, BCPC, Farnham, Surrey, UK, pp. 755-762 (2000).

[14] Wong F P, Wilcox W F. Distribution of baseline sensitivities to azoxystrobin among isolates of Plasmopara viticola. Plant Disease 8, 275-81 (2000).

[15] Fraaije B A, Lucas J A, Clark W S, Burnett F. QoI resistance development in populations of cereal pathogens in the UK. In: The BCPC Conference Pests and Diseases. The British Crop Protection Council, Alton, Hampshire, UK, pp. 689-94 (2003).

[16] Pasche J S, Piche L M and Gudmestad N C. Effect of the F129L mutation in Alternaria solani on fungicides affecting mitochondrial respiration. Plant Disease 89,269-78 (2005)

[17] Bartlet D W, Clough J M, Godwin J R, Hall A A, Hamer, Parr-Dobrzanski B. The strobilurin fungicides. Pest Management Science 58, 649-62 (2002).

[18] Sierotzki H, Kraus N, Assemat P, Stanger C, Cleere S, Windass J. Evaluation of resistance to QoI fungicides in Plasmopara viticola populations in Europe, in Modern Fungicides and Antifungal Compounds IV, ed. by Dehne HW, Gisi U, Kuck KH, Russell PE and Lyr H. BCPC, Alton, UK, pp. 73-80 (2005).

[19] Yamaguchi I, Fukimura M. Recent topics on action mechanisms of fungicides. Journal of Pesticide Science 30, 67-74 (2005).

[20] Sierotzki H, Frey R, Wullschleger J, Palermo S, Karlin S, Godwin J, Gisi U. Cytochrome b gene sequence and structure of Pyrenophora teres and P. tritici-repentis and implications for QoI resistance. Pest Management Science 63, 225-33 (2007).

[21] Tekuaz A. A numerical scale to classify reactions of barley to P. teres. Canadian Journal of Plant Pathology 7, 181-83 (1985).

[22] Lockley D, Clark W S. Fungicide Dose-response Trials in Wheat: the Basis for Choosing 'Appropriate Dose'. London, UK: HomeGrown Cereals Authority: HGCA Project Report no.373 (2005).

[23] Oxley S J P, Hunter E A. Appropriate fungicide doses on winter barley: producing dose-response data for a decision guide. HGCA project report No.366. www.hgca.co.uk (2005).

[24] Semar M, Strobel D, Koch A, Klapappach k, Stammler G. Field efficacy of pyraclostrobin against populations of Pyrenophora teres containing the F129L mutation in the cytochrome b gene. Journal of Plant Disease and Protection. 114, 117-19 (2007).

[25] Fisher N, Brown A C, Sexton G, Cook A, Windass J, Meunier B. Modelling the Qo site of crop pathogens in Saccharomyces cerevisiae cytochrome b. European Journal of Biochemistry 271, 2264-71 (2004). 